9. J. R. R. Tolkien, "On Fairy-Stories," Tree and Leaf (Boston: Houghton Mifflin, 1964), 3-84; Mark J. P Wolf, Building Imaginary Worlds: The Theory and History of Subcreation (New York: Routledge, 2012).

\title{
Sensation Fiction
}

\author{
MARLENE TROMP
}

$I^{1}$ $\mathrm{N}$ spite of our recognition of the blurriness of generic boundaries, we tend to reassert them where sensation fiction is concerned. There is value in understanding sensation in new ways-and potential political consequences when we do not. This is especially significant now that our critical study of sensation fiction has matured to the point that it is possible to offer reviews of the critical field, like those by Anne-Marie Beller and Mark Knight. ${ }^{1}$ Even the most important work in the field on sensation has often reinforced the binary between sensation and realism. ${ }^{2}$ The boldest moves have been made by scholars like Richard Nemesvari, who argues that Hardy understands and deploys melodrama and sensation in order to offer cultural and ideological critiques. ${ }^{3}$ While challenging our sense of the genre's impact and engagement with realist fiction, it distinguishes sensation as a distinct mode. Emily Steinlight offers a similar analysis of Eliot's fiction and realist fiction more broadly (as I did in The Private Rod). ${ }^{4}$

In spite of the careful way in which critics seek to navigate the complex terrains of generic meaning, even these studies have persisted in treating sensation fiction as an excessive hyper-genre of the "not real"-a bit of flash and dazzle that emerged (or could be consciously deployed) in relation to or in realist fiction for effect. This seems striking given the fact that we have learned to explore real cultural phenomena like marital violence, the body, property law, and science in new ways from sensation fiction. While sensation often supplies the leverage to read against the grain, we often (perhaps unconsciously) return it to its generic box when we have completed the task.

One of the early critical treatments of sensation sought to blur the borders between genres. In his 1982 essay on sensation fiction, Patrick Brantlinger makes a Derridean argument that it is "impossible not to 
mix genres," ${ }^{5}$ referring to the relationship between sensation and Gothic fiction and the detective novel, not realism. We must take Brantlinger's argument further. Our discussions of sensation have yet to sufficiently addresses the fundamental Derridean notion that these binaries create hierarchies-hierarchies that are invested with and produce political and social effects. Treating sensation as an entirely distinct and subordinate term in this binary suggests the genre's separation from the real(ist). There are potential political stakes to excluding realism from our analysis of sensation and even to reestablishing the distinctions that we have found so useful. While no fiction is "real," generically subordinating sensation supplies both affective and ideological resistance to imagining that the matter of sensation fiction engages what is real-not as reportage on actual historical events, but in its portrayal of real social and affective phenomenon through the medium of fiction (one of the ways we understand realist fiction). Wives were sometimes confined to lunatic asylums, both women and men did try to murder inconvenient spouses-sometimes successfully. Infidelity, bigamy, deception, and interpersonal violence marked and sometimes saturated people's lives. The narrative of life offered in sensation fiction and realist fiction are not two poles-reality and unreality-but instead intimately related in ways with which we have often failed to grapple meaningfully.

Treating sensation as primarily hyperbolic, symbolic, or gestural permits us to dismiss the matter of sensation and the political dynamics that inhered within them. By way of extended metaphor, we might consider Anita Hill's testimony during the Senate hearings for Clarence Thomas's Supreme Court nomination in 1991. Hill's narrative was repeatedly dismissed in the news media and public comment as "sensational" though many acknowledged Hill's significance and cultural impact. The rendering of Hill's testimony as "sensational"-excessive, dramatic, even titillating-had consequences. Americans crafted a binary structure in which what Hill experienced was, at best, marginal, and, at worst, fantasy. Sixty percent of Americans believed the testimony was an "embarrassing spectacle" and the same percentage believed that she had "thought some of this stuff up in her head. Women do that sometimes." The majority of Americans believed that Hill's story was a sensational fiction.

From its cultural birth, we treated sexual harassment as "sensation," something "unreal," or at the very least, truly exceptional. We obliquely distinguished it from "reality," even while we explicitly asserted the value of the conversation. These often-subtle gestures not only made it 
easier to place Clarence Thomas on the bench, but also to permit cases like those of Harvey Weinstein and Matt Lauer to be largely obfuscated for decades and for feminists to brace themselves for backlash when they no longer are. Treating sexual harassment like a marginal unreality is a Derridean failure that lends impunity to the harassers.

Similarly, treating sensation as if its fictional narratives somehow represent an unreality teaches us to dismiss this representation of murder, infidelity, and deception, along with the political dimensions of those social problems. Bounding sensation in this way may shore up a sense of cultural safety and normalcy, but it also maintains the status quo. Failing to recognize the porousness of sensational fiction and realist fiction, sensation fiction and the real-and not just as a one-way conduit that channels some sensation into realism-permits us to treat the content as an aberration.

We, as critics, must stop treating "sensation" as a synonym for "unrealistic." We must come to think of the word "sensation" as we do the word "natural"- to pause and imagine whether we are deploying it in an unselfconscious way that too loosely imagines it to have firm and clear boundaries and to exist in a zone that contrasts a Victorian reality or the story of reality, which was-as we might imagine-much more mundane. The real has much more of the sensational than we have allowed and opening ourselves to its meaning may help us read not only the fiction, but the social politics of the period, in new ways.

\section{Notes}

1. These studies note sensation's broader impact in the field and increasing respectability as an object of study (Beller) and consider our ongoing fascination with sensation (Knight). Anne-Marie Beller, "The Fashions of The Current Season': Recent Critical Work on Victorian Sensation Fiction," Victorian Literature and Culture 45, no. 2 (2017): 461-73; Mark Knight, "Figuring Out the Fascination: Recent Trends in Criticism on Victorian Sensation And Crime Fiction," Victorian Literature and Culture 37, no. 1 (2009): 323-33.

2. In the epigraph to her important Companion to Sensation Fiction (Maldon: Blackwell, 2011), Pamela K. Gilbert quotes Anthony Trollope's assessment that novels cannot be divided into two schools, sensational and realistic. She remains off this terrain in her introduction however (Anthony Trollope, "On English Prose Fiction as a Rational Amusement," in Four Lectures by Trollope, ed. M. L. Parrish 
[London: Constable, 1938]). "Realism and Sensation Fiction" by Daniel Brown, for example, makes the case that the differences between the two genres can be "difficult to discern," but notes that, while the subject matter may be the same (crime, infidelity, murder), the approach distinguishes the genres. The latter move, of course, structurally reasserts the binarism he earlier critiqued. Daniel Brown, "Realism and Sensation Fiction," in A Companion to Sensation Fiction, 105.

3. Richard Nemesvari, Thomas Hardy, Sensationalism, and the Melodramatic Mode (New York: Palgrave Macmillan, 2011).

4. Emily Steinlight, "Why Novels Are Redundant: Sensation Fiction and the Overpopulation of Literature," ELH 79, no. 2 (2012): 501-35, 504. She cleverly reads against the frame of W. R. Greg's notion of redundancy and argues that "criticism itself relies on the conception of an overcrowded literary field in need of regulation." See also Marlene Tromp, The Private Rod: Marital Violence, Sensation, and the Law in Victorian Britain (Charlottesville: University of Virginia Press, 2000).

5. Patrick Brantlinger, "What Is 'Sensational' About the 'Sensation Novel'?” Nineteenth-Century Fiction 37, no. 1 (1982): 1-28, 2.

6. Elizabeth Kolbert, "The Thomas Nomination; Most in National Survey Say Judge Is the More Believable," The New York Times, October 15, 1991.

\section{Sentience}

ANNA HENCHMAN

T 1789, Jeremy Bentham entered a longstanding debate about 1 sentience (the ability to perceive something physical like warmth or cold) by asserting that animals have rights because they can feel pain: "The question is not Can they reason? nor, Can they talk? but, Can they suffer?" Sentience refers to a baseline form of perception, less complex than cognition or consciousness. It implies the presence of senses, but not necessarily the specialized senses of sight, hearing, smell, or taste. While scholarship has fruitfully investigated how Victorian writers 